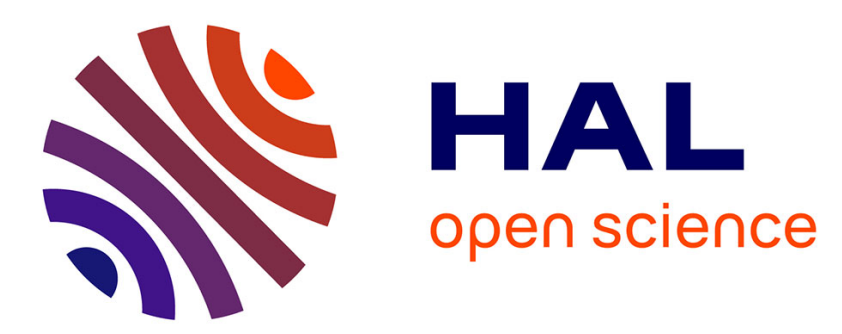

\title{
Synergico: a method for systematic integration of energy efficiency into the design process of electr(on)ic equipment
}

\author{
Damien Evrard, Daniel Brissaud, Fabrice Mathieux
}

\section{- To cite this version:}

Damien Evrard, Daniel Brissaud, Fabrice Mathieux. Synergico: a method for systematic integration of energy efficiency into the design process of electr(on)ic equipment. International of Sustainable Engineering, 2013, 6 (3), pp.225-238. 10.1080/19397038.2012.704431 . hal-00881278

\section{HAL Id: hal-00881278 https://hal.science/hal-00881278}

Submitted on 8 Nov 2013

HAL is a multi-disciplinary open access archive for the deposit and dissemination of scientific research documents, whether they are published or not. The documents may come from teaching and research institutions in France or abroad, or from public or private research centers.
L'archive ouverte pluridisciplinaire HAL, est destinée au dépôt et à la diffusion de documents scientifiques de niveau recherche, publiés ou non, émanant des établissements d'enseignement et de recherche français ou étrangers, des laboratoires publics ou privés. 


\title{
Synergico: a method for systematic integration of energy efficiency into the design process of electr(on)ic equipment
}

\author{
Damien EVRARD ${ }^{\mathrm{a},{ }^{*}}$, Daniel BRISSAUD ${ }^{\mathrm{a}}$, Fabrice MATHIEUX ${ }^{\mathrm{a}, \mathrm{b}}$ \\ a: G-SCOP laboratory, University of Grenoble, Grenoble, France
}

b: Institute for Environment and Sustainability, European Commission Joint Research

Center, Ispra, Italy

*: Corresponding author

Damien Evrard

Laboratoire G-SCOP,

46 avenue Félix Viallet, 38031Grenoble CEDEX 1, FRANCE

Ph: +33456529813

Fax: +33476574695

Email: damien.evrard@g-scop.grenoble-inp.fr

Daniel Brissaud

Laboratoire G-SCOP,

46 avenue Félix Viallet, 38031Grenoble CEDEX 1, FRANCE

Ph: +33476827006

Fax: +33476574695

Email: daniel.brissaud@g-scop.grenoble-inp.fr

Fabrice Mathieux

European Commission - Joint Research Centre

Institute for Environment and Sustainability (IES)

Sustainability Assessment Unit (H08)

Via Enrico Fermi 2749 - TP 270

I - 21027 Ispra (VA) - Italia

Ph: +390332789238

Fax: +390332786645

Email: fabrice.mathieux@jrc.ec.europa.eu 


\title{
Synergico: a method for systematic integration of energy efficiency into the design process of electr(on)ic equipment
}

\author{
This paper presents an overall design method to better consider the energy \\ consumption of electrical and electronic equipment during the use phase. This \\ aspect is often considered as the most important environmental aspect in active \\ electrical and electronic equipment during its lifecycle. The proposed method, \\ called "Synergico", characterizes the product energy efficiency according to its \\ modes, its functions and its sub-assemblies. It also articulates three tools: one \\ assessment tool, one improvement tool, and one environmental check tool. These \\ tools are integrated along a typical product design process. The method therefore \\ helps designing more energy efficient products without compromising other \\ performances such as ergonomics, functional performances, security, \\ recyclability or costs. The three tools and the overall method are presented. A \\ case study illustrates the way it works and is discussed.
}

Keywords: ecodesign method; energy efficiency, electrical and electronic products

\section{Introduction}

Energy consumption has been a major concern for several decades. Indeed, both private and public sectors have been aware that they need to find solutions to secure their supplies in addition to complying with obligations to reduce their emissions of greenhouse gases in a sustainable way $(\operatorname{COM}(2006) 545, \operatorname{COM}(2010) 639)$. The European Commission defined five strategies to cope with this issue. One of them is entitled "Achieving an energy-efficient Europe" and aims at a 20\% saving by 2020 by imposing energy efficiency criteria in all economic sectors (COM(2010)639). Directive 2009/125/EC proposes to set ecodesign requirements for energy-related products (ErP), directing manufacturers of electrical and electronic equipment and other energy-related equipment towards more energy efficient products. The potential savings thanks to energy efficient products is estimated to be between 20 to $30 \%$ of the energy consumed 
during the use phase for the product categories selected in the ErP directive.

This directive amends the previous EuP (Energy-using Products) directive (2005/32/EC). It states that "energy saving is the most cost-effective way to increase security of supply and reduce import dependency" and also that "action should be taken during the design phase of energy-related products".

Besides, Energy consumption is highly considered in numerous countries with programmes such as Energy Star in the USA, the top-runner programme in Japan, the SEPA certified products in China, the Canadian EcoLogo, or the Korean Green Mark. Although efficient electr(on)ics are essential to achieve notable energy savings and to reduce environmental impacts, most products on the market show a poor efficiency combined with a high potential for energy savings (Sauer et al. 2002, Kammerer 2009). According to the survey carried out by Kammerer (2009), only $23 \%$ of the companies had implemented at least one energy efficiency improvement on more than $50 \%$ of their products between 2006 and 2009. This can be explained by the lack of legislative objectives in this respect which has been partly solved by the ErP directive and its implementing measures. A second explanation is the lack of methods to design energy efficient products. The industry often argues that it needs systematic methods in order to comply (or overcome) with always more stringent objectives set by regulators.

Indeed, companies manage their design processes in their own ways but they can be generalised "as a chain of tasks that must be carried out when a new product is developed, tested, refined and marketed" (Luttropp and Lagerstedt 2006). Pahl and Beitz (1996) and ISO/TR 14062 (ISO 2002) proposed models which aim at representing the design process in companies, based on individual steps such as planning, conceptual design, detailed design, prototyping. Besides, ISO/TR 14062 focuses on the integration of environmental aspects into product design. 
Nevertheless, examples of successfully ecodesigned electronic products can be found in the literature like the ecomouse (Schneider and Salhofer 2008). Many simple and sophisticated ecodesign tools include energy consumption considerations (Unger $e t$ al. 2008, Vallet et al. 2009). A closer look to these tools shows that a rough estimate of energy consumption in use is taken into account, i.e. either as an average amount of energy, or as a function of average power and time spent in each mode.

Among industry-oriented tools, Ecodesign Pilot@ (Vienna TU 2012) provides guidelines to improve a modelled product according to its environmental impacts during its lifecycle. In this tool, energy consumption in use is nonetheless considered by a total amount of energy consumed; EDIT® (Eco-Design Indicator Tool) (Wrap 2012) only considers the amount of energy per average use and the average number of uses per year; Eco-itß (Pré 2012b) and SimaPro® (Pré 2012a) developed by the same editor consider a total amount of energy during use. Finally, EIME® (Environmental Impact and Management Explorer) (Bureau Veritas 2012) is a tool adapted to electr(on)ic products and considers several predefined modes and the power and share of time spent in each mode.

Even if product models are mature enough and could support these considerations (Brissaud and Tichkiewitch 2001) and several methods have been published (Li et al. 2008; Zhang and Li 2010), these environmental assessment tools unfortunately do not provide a guide to steer product design towards better energy efficiency, as highlighted by Hernandez-Pardo et al. (2011).

This paper introduces Synergico, a method which characterizes the product energy efficiency by its modes, functions and sub-assemblies and articulates three tools along the product design process. Its purpose is to steer the energy consumption of a product during its use while its design is ongoing. Each tool respectively aims to assess 
the energy consumption, to help designers improve their product, and to check impact transfers. They are jointly presented in this paper to show the coherence and usefulness of this approach (section 2). Then, a case study illustrating the use of the method during a new product design project is developed in section 3 . The paper ends with a discussion about the method and its possible improvements.

\section{Characteristics of the Synergico method and its tools}

The proposed method was specified to help designers to better consider the energy consumption of their products and to facilitate its integration as any other design criteria (quality, costs, delays, safety, functional performances, etc.) (Rünger et al. 2011). It streamlines the energy criterion in order to help define quantified objectives in the design specifications. This ensures an objective has actually been specified in the product design through a controlled process and to follow up the evolution of the estimated or measured consumption throughout the design stages.

Thus, the proposed method is meant to be generic enough to be applicable for any electr(on)ic equipment and adaptable to any corporate design processes. It should also comply with the regulations and Energy Star objectives. It also helps designers to consider the objectives which will drive the design from the start; either considering a Typical Energy Consumption or Operational Modes approaches (ENERGY STAR 2011) with several user scenarios. The importance of this step is explained in Luttropp and Lagerstedt (2006).

An important aspect in the method is the definition of objectives for the project. This step takes place at the beginning of the project according to internal and external goals such as regulations, labels (Energy Star, ecolabels, etc.), codes of conduct, government contracts, or customer requirements. Four objectives for the method had 
been identified: (a) to enable an easy integration in the corporate design process; (b) to monitor the product energy efficiency and design indicators; (c) to provide design strategies; (d) to consider environmental issues.

\section{a) Integration in the corporate design process}

Compared to ISO/TR 14062 design process, particularities were observed in the design processes of the companies involved in the development of the method. For example, there was no distinction between planning and conceptual design. The corporate strategy can be considered in the method while defining the objectives of a new design project and be integrated within the management tools which have already been defined (milestones, reviews, capitalisation of knowledge, etc.).

ISO/TR 14062 advocates considering environmental aspects in the early design stages. Based on this standard, the Synergico method considers the following six design steps: planning, conceptual design, detailed design, trials/prototype, production/market launch, and product review.

The method helps include energy efficiency considerations at every step of the design process through the use of three tools, namely the in-use energy consumption tool (IUE) described in (b), the guidelines described in (c), and the lifecycle check tool described in (d), as shown in figure 1. 


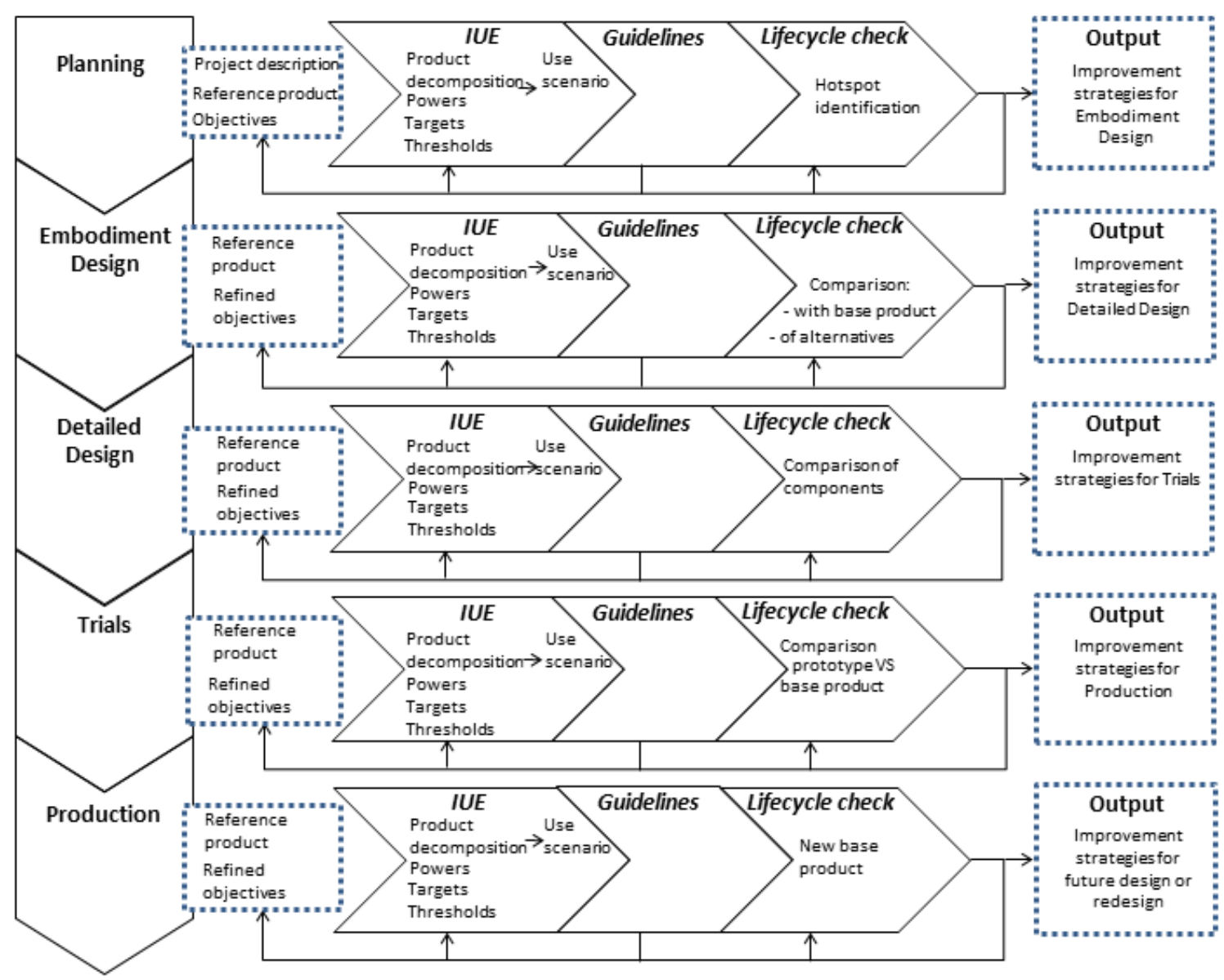

Figure 1: Summary of the Synergico method in the design process.

For each design phase, the designers can fill in the inputs of each tool: the product architecture; the best person(s) who can provide information; which tool is used; detailed instructions about the use of the tool; output data from the previous phase.

At the beginning of each phase, design data and more specific information about the product (represented inside dotted boxes in Figure 1) are used as input into the IUE tool.

\section{b) Monitoring product energy consumption and design indicators}

Product energy consumption is an environmental aspect which is a function of the power consumed to fulfil the different functions and the time spent in each operating 
mode and function. This second parameter is affected by the users and will determine the lifetime pattern of the product (Domingo et al. 2012). Therefore several user scenarios should be considered because the consumption may vary with different users. In Synergico, an electr(on)ic product is considered as an assembly of components with their own physical characteristics. The level of detail necessary to specify the number of components depends on the project goals, i.e. a finer specification is necessary to identify smaller energy inefficiencies. At component level, the basic contributor to power is the power available for each component of the product i.e. the installed power. It results from the inherent characteristics of the component and is usually provided by the component manufacturer on datasheets. Alternatively, direct measurements on a prototype or a previous similar assembly are possible. It is a fixed value resulting from the choice of component made by the designer, and will remain the same during the whole product lifetime. Mukherjee et al. (2007) showed that the power of a single component may vary depending on the job it performs. The power needed by the component to perform a specific job is defined as a load coefficient multiplied by the installed power. This implemented power is the power needed by a component to perform a specific job. This factor depends on the job that a component has to perform and is defined by the software code implemented to manage the component. The energy consumption of the component will be affected by this implemented power and the duration during which it will be activated by the computer programme implemented in the product. This programme manages the opening, closing and intensity of the input current provided to the component depending on the jobs that it has to perform.

A job can be seen as any actions that the product can realize in order to answer the user needs. Hence, the lifetime of a product can be seen as a combination of jobs that can be performed simultaneously or sequentially (ENERGY STAR 2009). For 
different users, different combinations of jobs will exist. That is the reason why the IUE indicator is calculated for several user scenarios.

Eventually, all these data are used to calculate the In-Use Energy consumption indicator (IUE) based on equation (1) below (after (Domingo 2012)) for every considered scenario and to monitor the compliance with the objectives defined earlier.

$$
I U E=\left\{\begin{array}{l}
\operatorname{IUE}(1)=\sum_{j=1}^{N j}\left(\sum_{i=1}^{N_{i}} P(i) \times J o b(i, j)\right) \times t_{j o b}(j)(1) \\
\vdots \\
\operatorname{IUE}(k)=\sum_{j=1}^{N j}\left(\sum_{i=1}^{N_{i}} P(i) \times J o b(i, j)\right) \times t_{j o b}(j)(k) \\
\vdots \\
\left.I U E\left(N_{k}\right)=\sum_{j=1}^{N j}\left(\sum_{i=1}^{N_{i}} P(i) \times J o b(i, j)\right) \times t_{j o b}(j)\left(N_{k}\right)\right)
\end{array}\right.
$$

where IUE(k) is the energy consumption indicator of the product for the $\mathrm{k}^{\text {th }}$ user scenario (in Wh); P(i) the implemented power of component $\mathrm{i}($ in $\mathrm{W})$; Job(i,j) the percentage of solicitation of component $\mathrm{i}$ to carry out job $\mathrm{j}$ (in \%); and $\mathrm{t} \mathrm{job}(\mathrm{j})(\mathrm{k})$ is the cumulative duration of job $\mathrm{j}$ during the product lifetime for the $\mathrm{k}^{\text {th }}$ user scenario (in hours).

In addition to the absolute value of this indicator (in Wh), the IUE equation can be used to identify the modes, functions and sub-assemblies that contribute the most to the energy consumption. This helps to monitor the evolution of the design and capitalises the tests carried out on various alternatives. The evolution of the indicator is tracked to ensure that the energy consumption will not diverge from the targets.

It is computable throughout the design project and is more accurate as the design specifications are defined since the product architecture, its modes and functions, which are also useful to identify user scenarios, and power for the different sub-assemblies at every mode and function are better known. 


\section{c) Elaborating strategies}

Strategies can be elaborated to improve the performance using the "Guidelines" tool.

Design specifications or product decomposition can therefore be modified. The lifecycle check tool is then used to identify hotspots or compare alternatives. The "Guidelines" tool (Bonvoisin et al. 2010) is an inventory of 59 guidelines specific to energy consumption. Designers can add new ones and use a filter to select only the few most relevant ones. The relevance of this kind of tool was shown by Luttropp and Lagerstedt (2006), Telenko et al. (2008), and Knight and Jenkins (2009) and contributes to building improvement strategies.

In Synergico, guidelines are defined according to Vezzoli’s definition as "procedures to orient a decision process towards given objectives" (Vezzoli and Sciama 2006). According to this definition, guidelines have two major functionalities: (1) before any implementation choices, they give a wide list of promising strategies; (2) after a choice, they allow the design to converge towards an objective.

Each guideline is a short sentence and a more detailed description is provided. They were collected from standards (e.g. Energy Star), regulation-related publications (e.g. EuP directive preparatory studies), conference proceedings and journals, and the experience of industrials involved in the project.

Eight criteria help the designers to select the guidelines according to the context: (1) stage in the design process; (2) department targeted by the guideline; (3) risk to have side effects; (4) level of application (product or component); (5) change of component or technology; (6) change in the product or design process; (7) power management scale (power or component); (8) change affecting one or several modes or the transition from one mode to another. After applying these filters, designers can select a few priority strategies (Bonvoisin et al. 2010). 


\section{d) Consideration of environmental issues}

In order to prevent a product with good energy efficiency from having higher environmental impacts on other lifecycle phases or other impact categories, an environmental screening of the product lifecycle needs to be done. The product can then be compared with another product with similar functions. This can also be useful to compare different alternatives during design.

Environmental impacts need to be considered as early as possible in the design process so as to create a product which is really efficient (Kengpol and Boonkanit 2011). Life Cycle Assessment (LCA) as defined in ISO 14040 (ISO 2006) has been chosen in Synergico as a basis to identify these impacts during the lifecycle of a product and to track possible impact transfers.

However, LCA presents a number of setbacks such as its complex application by practitioners, or the need for fully defined products (Millet et al. 2007, Reap et al. 2008, Ramani et al. 2010). It is consequently impossible to use it in early design stages (Telenko et al. 2008) unless dramatic simplifications are made (Nielsen and H. Wenzel 2002). That is the reason why a simplified lifecycle check tool is included in Synergico (Domingo et al. 2011).

This lifecycle check tool compares the environmental impacts of the product along its lifecycle with a reference product which had previously been assessed with a more sophisticated LCA tool in order to verify that a solution improving energy efficiency in use does not entail impacts in the other phases. This tool performs a very simplified LCA aimed at helping designers to take the best decision but it cannot replace a full LCA according to the ISO 14040 standard.

Two outcomes are possible: (1) the design performances are not satisfying and the product needs to be improved before going to the next phase; (2) the design passes 
to the following step. In the first case, improvement strategies can be identified thanks to the guidelines.

\section{The Synergico method applied to a case study: a postage metre}

\subsection{Context of the case study}

The product studied was a postage meter. This professional equipment was destined to medium-sized enterprises to frank mail. Its main function was to stamp a letter at the adequate fee and to charge the amount to a virtual purse. The meter was a typical electr(on)ic equipment, made of mechanical and electr(on)ic parts.

The method and tools were tested with the manufacturer of the product during its development. The three tools have been implemented in prototypes using classical MS Excel spreadsheets. This case study was based on information provided by the company and aimed at illustrating how Synergico could be used during the design of efficient electr(on)ic products.

The observations of the usual practices in this company showed that product energy consumption was considered during most of the design phases but only once in each phase as follows:

- Planning: energy requirements were defined in the product specifications, in particular the standby consumption;

- Conceptual design: the power supplies needed for the product components and sub-assemblies were assessed;

- $\quad$ Conceptual and Detailed design: informal measurements could be made to verify the compliance with consumption objectives;

- $\quad$ Prototype: measurements according to the specifications given by standards (e.g. 
Energy Star) could validate the final consumption.

These practices illustrate that no real systematic monitoring of the energetic performances through the design process is currently implemented in companies. On the one hand, the assessment of the needed power supply was independent of the search for energy efficiency: it was carried out by the electronics experts and was not discussed by the design team. On the other hand, the assessments made during the design were informal and only emphasized the need for more efforts to respect the objectives but did not help to steer the consumption.

The design team, in particular, the different technical experts (electronics, mechanics and software) had to find the best compromise between cost, energy losses and time of transition between modes. In most cases, energy efficiency was considered late in the design and therefore the choice of components or product architecture was narrower than if made earlier.

For this case study using Synergico, the design team was composed of representatives from different departments, which was concordant with Kengpol and Boonkanit (2011): project management, electronics, mechanics, software, purchases, marketing, and ecodesign. Other companies using Synergico may have a different composition for their design team, such as the decomposition in sub-projects proposed by Johansson and Magnusson (2006). In this case, project management, also included sub-project leaders and a project leadership support group which consisted of additional positions such as an assistant project leader, a project administrator and a quality coordinator.

The product to be developed here was the next generation of an existing meter, therefore a product from the previous generation was used here as a reference to be redesigned. 
The reference product possessed five functions which were likely to exist in the new design. The letters were selected from a mail stack and carried, individually, to an automatic wetting system which sealed the mails. Then, they were weighed and a stamp, at the correct fee and in accordance with the specifications of the local postal service, was printed. Finally, the franked mails were stacked, waiting to be collected and brought to the post office. A modem enabled the communication with the postal office in order to manage an online purse and to automatically charge the fees to the user.

Two new functions were added: a static weighing for oversized mails which cannot feed into the machine, and a label feeder to automatically add the address of the recipients. The product was destined to the European market and the company was willing to aim at Energy Star targets.

The application of the tools will be described in details for the planning phase as and summarized for the other design phases.

\subsection{Using Synergico during the planning phase}

"Planning and task clarification" aims at defining the goals and scope of the project since little information about the product is known and the designers have a lot of freedom (Luttropp and Lagerstedt 2006).

As shown in figure 1, the information defined during the Project description about the product was firstly used in the IUE tool (see sections 3.2.1 to 3.2.7). Then, the guidelines entered into play, and finally, the lifecycle check tool was used. Depending on the outcome, improvements would be carried out or the project would enter into the conceptual design stage. 


\subsubsection{Project definition}

Project definition, i.e. giving general information about the product (name, category, etc.), enables designers to clarify the scope of the project.

In the case of a redesign, the choice of an existing product as a reference for the future product is also very important for comparison with the new design. In this example, the previous generation of the postage meter was used but a benchmark of a competitor's product would be possible. The lifespan of the product was defined as seven years.

This operation is usually done once and for all during the planning phase. However, it can be reviewed later, if new issues arise.

\subsubsection{Project objectives}

Luttropp and Lagerstedt (2006) stated that "since the goal/specification phase is the most crucial as far as product performance and properties are concerned, this is where the 'green issues' must enter". Therefore, this phase should define realistic energy goals based on internal and external objectives. In the tool, two parameters are considered by default for the modes: latency and maximum power. A good balance between both parameters is important to avoid creating a product with low energy consumption but slowly reacting to user's commands. As the design project progresses, these objectives can be refined or updated along with the knowledge about the product.

In this case study, the goal was compliance with the ErP directive (2009/125/EC), with the objectives currently applicable, i.e. a maximum of $1 \mathrm{~W}$ in standby and $0 \mathrm{~W}$ when the product is off. In other contexts, more ambitious objectives could obviously be targeted. 


\subsubsection{Modes}

The product was to be used in several modes during its time of use. The most common modes are the $O n$ and $O f f$ modes, respectively when the "product is connected to a power source and is actively producing output", and "the power state that the product enters when it has been [...] switched off" (ENERGY STAR 2009). An additional standby mode, with low power consumption and faster wakeup time is often defined and expected by the regulation. At this early step, only these three modes seemed relevant, considering the level of details in the product's structure.

Nevertheless, as a reference product was known, a total of six modes were expected to be encountered and were therefore entered in the IUE tool:

- 4 were a subset of the on mode:

O On-Ready: the machine is waiting for a task;

$\circ$ On-Active com: the machine is communicating with the postal service or with a server to update the software;

○ On-Active printing : the machine is printing a stamp;

On: mode for other actions when the machine is on;

- Standby: a low power mode activated when the machine is not used after a certain time;

- Soft off: the machine is turned off through the software;

- Hard off: the user presses a physical button to turn it off.

\subsubsection{Functions}

The main function of the product was to frank mails. To accomplish this task, the process in Section 3.1 had to be decomposed into sub-functions. These sub-functions were inactive in certain modes and consequently had to be linked with the right ones. 
Several functions might work in the same mode, e.g. a man-machine interface may have been active in all the on sub-modes and also in standby for the display of a message.

The time share during the product lifespan is given in table 1 .

\begin{tabular}{|c|l|l|r|}
\hline$\#$ & \multicolumn{1}{|c|}{ Function } & Related mode & Time share \\
\hline F1 & Setting up & On & $100 \%$ \\
\hline F2 & Selection & On-Active printing & $58 \%$ \\
\hline F3 & Weighing & On-Active printing & $96 \%$ \\
\hline F4 & Franking & On-Active printing & $37 \%$ \\
\hline F5 & Wait & On-Ready & $100 \%$ \\
\hline F6 & Additional functions & On & $100 \%$ \\
\hline F7 & Shut down & Off & $100 \%$ \\
\hline
\end{tabular}

Table 1: Functions, their corresponding mode, and the percentage of time each function spends in a given mode for the postage meter.

In Table 1, not all the modes defined in 3.1 were linked to a function. This can be explained by the fact that the functions of the product are only roughly defined at this stage and this first model is not detailed enough to encompass all the modes.

The percentages in the right column correspond to the amount of time each function works during its related mode. For instance, the duration of the function "Selection" was measured to last $58 \%$ of the time spent in the mode "On-Active printing", whereas the "Franking" function only lasted $37 \%$ of the total duration of this mode.

\subsubsection{Structure}

After the functions had been defined, the designers started thinking of how to carry them out. During the planning stage, they could only use their expertise and the reference product to write down a first version of the product structure with the following sub-assemblies:

- A base which contains the CPU, the trays, and the mail carrying system (F1, F2, 


\section{F5, F7);}

- A feeder: the system for labelling the envelopes (F6);

- Scales: to weigh the mails (including the oversized mails) (F3);

- A printer: to print the stamp (F4);

- A security system which manages the transactions between the postal office and the user (F6);

- A modem for communication (F6).

\subsubsection{Scenarios}

Energy consumption varies with the way the product is operated by users, which influences the time spent in the different modes during the product lifetime (Aoe 2007). In addition, user actions can mitigate the efficiency of the design (Elias et al. 2009) and therefore, one or several actual user scenarios are preferable to an optimal but unrealistic one.

In Synergico, the definition of user scenarios is important to obtain relevant and realistic IUE indicators. To do so, the participation of the marketing department which may have data about the customers' behaviours and how they use the equipment is interesting. The problem is that these data are hardly available (Sauer et al. 2002).

In the present case study, the designers considered two user scenarios: (1) a "classical" scenario where the user did not change the default settings and the machine was never shut down; (2) a "nightly shut down" scenario where the user turned off the machine after working hours. The input data were the share of time spent in the different modes during the product's lifetime (Table 2) 


\begin{tabular}{|l|r|r|}
\hline \multicolumn{1}{|c|}{ Mode } & $\begin{array}{c}\text { Scenario 1: } \\
\text { Classical }\end{array}$ & $\begin{array}{c}\text { Scenario 2: } \\
\text { Nightly shut down }\end{array}$ \\
\hline On-Active communication & $0.05 \%$ & $0.05 \%$ \\
\hline On-Active printing & $0.10 \%$ & $0.10 \%$ \\
\hline On-Ready & $99.85 \%$ & $31.10 \%$ \\
\hline Off & $0.00 \%$ & $68.75 \%$ \\
\hline
\end{tabular}

Table 2: Example of two user scenarios during planning.

\subsubsection{Power}

The last parameter necessary to calculate the indicator is the power consumed by the sub-assemblies in each mode. This step relies on the mechanical and electronic experts as they are used to deal with such values when they define the components needed in the product. Domingo et al. (2012) gave the details of the calculations of the IUE indicator.

Using the reference product and the expertise of the designers, it was possible to obtain IUE values. The results given by the IUE tool (Figure 2) was the value of the indicator for both scenarios: $376 \mathrm{kWh}$ during the product lifespan for scenario 1 , and $124 \mathrm{kWh}$ for scenario 2 ; with the largest contribution for the function "Wait" in the "OnReady mode" and in the security system.

Figure 2: IUE results during planning showing the contribution of the functions. 


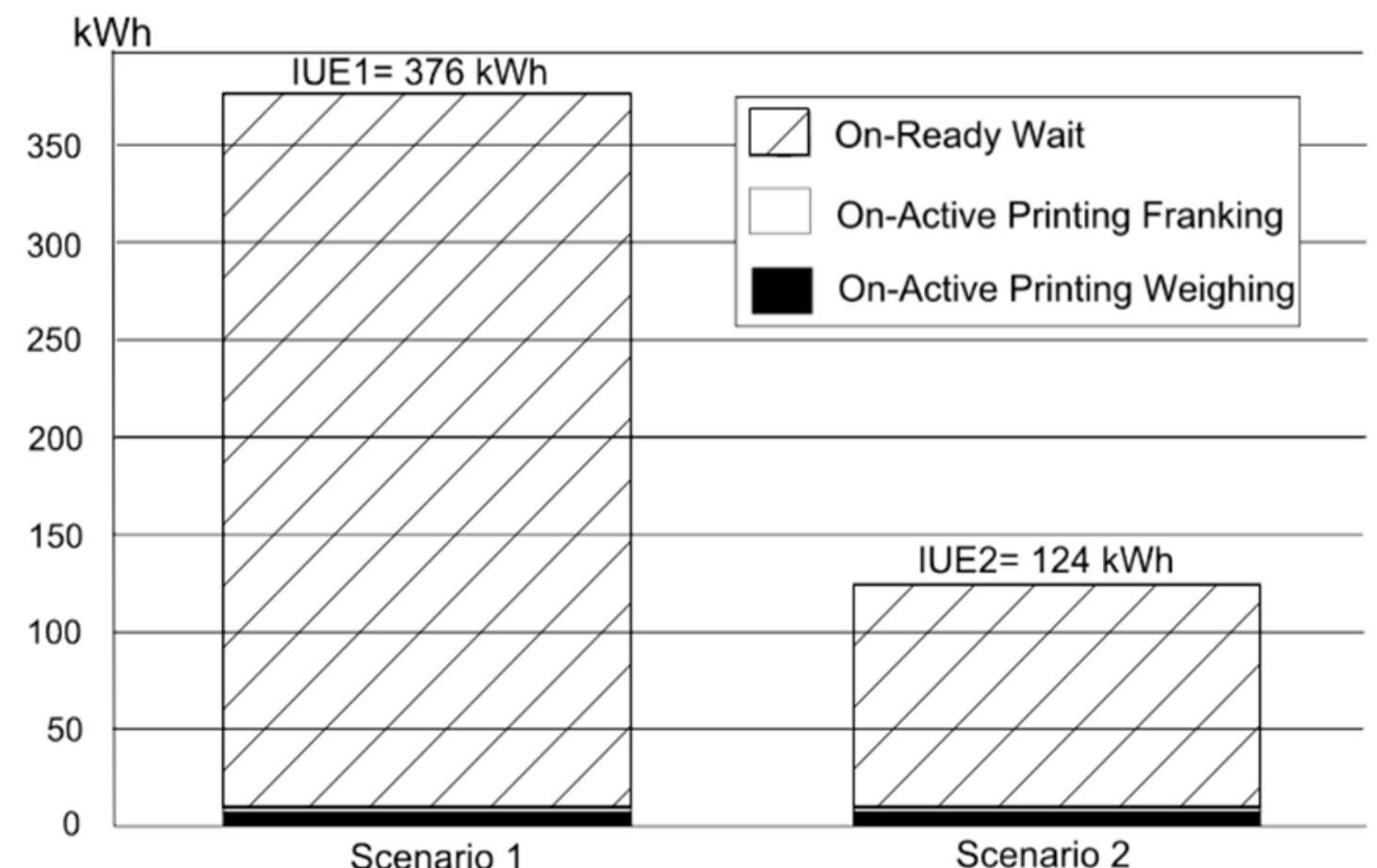

Figure 2: IUE results during planning showing the contribution of the functions.

The difference between both scenarios was due to the time spent in the on-ready and off modes (Table 2) which differed because the product was shut down at night in scenario 2 and always on in scenario 1.

This first result provided the designers with a first indication of where to improve the product energy efficiency but not which strategies may have worked.

\subsubsection{Guidelines}

The designers used the guidelines to identify relevant suggestions of ways of improvement. They filtered the 59 guidelines according to the eight criteria given in section 2 to extract the most interesting ones at the present stage (Bonvoisin et al. 2010).

The selection of criteria was up to the designers who decided which ones could be applied to their product and served their purpose. In this example, the designers had filtered with the following five criteria corresponding to the context and the needs: 
- $\quad$ Current design process phase: Planning;

- $\quad$ Risk to have side effects on the project: this criterion is about the decision level concerned to apply this guideline (in this case, project team);

- Functional changes: i.e. guidelines to redefine a function belonging to a subassembly, a product, a system or all;

- Change in the product: solutions directly applicable to the product;

- Modes impacted: one, several, or the transition from one mode to another.

The selection, using these 5 criteria returned eight guidelines (Table 3), whose feasibility was discussed within the design team (column "Comment" in the table):

\begin{tabular}{|c|c|c|}
\hline$\#$ & Guideline & Comment \\
\hline 1 & $\begin{array}{l}\text { Prevent any activity during } \\
\text { standby }\end{array}$ & $\begin{array}{l}\text { To ensure the security of the transactions between } \\
\text { the user and the postal office, the security device } \\
\text { must be powered constantly; therefore this } \\
\text { guideline is not relevant for this product. }\end{array}$ \\
\hline 7 & $\begin{array}{l}\text { Provide energy saving } \\
\text { functions }\end{array}$ & $\begin{array}{l}\text { This guideline is a requirement for Energy Star, so } \\
\text { the designers decide to keep it to comply with the } \\
\text { label. }\end{array}$ \\
\hline 8 & $\begin{array}{l}\text { Have an easily accessible } \\
\text { power switch }\end{array}$ & $\begin{array}{l}\text { This guideline is a requirement for the ErP } \\
\text { directive, so the designers decide to keep it to } \\
\text { comply with the regulation. }\end{array}$ \\
\hline 18 & $\begin{array}{l}\text { Plan for an automatic } \\
\text { shutdown }\end{array}$ & $\begin{array}{l}\text { A marketing decision is that the product must be } \\
\text { ready to be used any time so this guideline would } \\
\text { be applicable only when one is sure there is no } \\
\text { need of the machine or there is no communication } \\
\text { with the postal office. This issue needs to be } \\
\text { explored further. }\end{array}$ \\
\hline 24 & $\begin{array}{l}\text { Plan for an automatic } \\
\text { activation of standby }\end{array}$ & \multirow{4}{*}{$\begin{array}{l}\text { The guidelines are interesting and are not likely to } \\
\text { complicate the work of the designers much, } \\
\text { therefore they are kept. }\end{array}$} \\
\hline 26 & $\begin{array}{l}\text { Activate standby by } \\
\text { default }\end{array}$ & \\
\hline 54 & $\begin{array}{l}\text { Offer users to set up the } \\
\text { energy savings functions }\end{array}$ & \\
\hline 57 & $\begin{array}{l}\text { Prevent the complete } \\
\text { removal of the energy } \\
\text { savings functions }\end{array}$ & \\
\hline
\end{tabular}

Table 3: Selection of guidelines during planning. 


\subsubsection{Addition of a standby mode}

Five out of the eight guidelines found were related to energy saving functions and the standby mode. The designers consequently decided to add this mode and a "wake up from standby mode" function, activating the relevant components, in the IUE tool. Besides, this mode is a requisite to comply with ErP and Energy Star. They also modified the scenarios to consider that the product passed to standby when left idle for a certain time (cf. Table 4). After feeding the tool with the relevant information on power, the IUE indicator for the product with a standby mode (Figure 3) showed a decrease from $376 \mathrm{kWh}$ to $251 \mathrm{kWh}$ in scenario 1 and from $124 \mathrm{kWh}$ to $82 \mathrm{kWh}$ in scenario 2 i.e. a $33 \%$ reduction of energy consumption for both scenarios.

\begin{tabular}{|l|r|r|}
\hline \multicolumn{1}{|c|}{ Mode } & Classical & Nightly shut down \\
\hline On-Active com & $0.05 \%$ & $0.05 \%$ \\
\hline On-Active printing & $0.10 \%$ & $0.10 \%$ \\
\hline On-Ready & $1.34 \%$ & $1.34 \%$ \\
\hline Standby & $98.51 \%$ & $29.76 \%$ \\
\hline Off & $0.00 \%$ & $68.75 \%$ \\
\hline On & $1.49 \%$ & $1.49 \%$ \\
\hline
\end{tabular}

Table 4: Scenario definition at planning with a standby mode. 


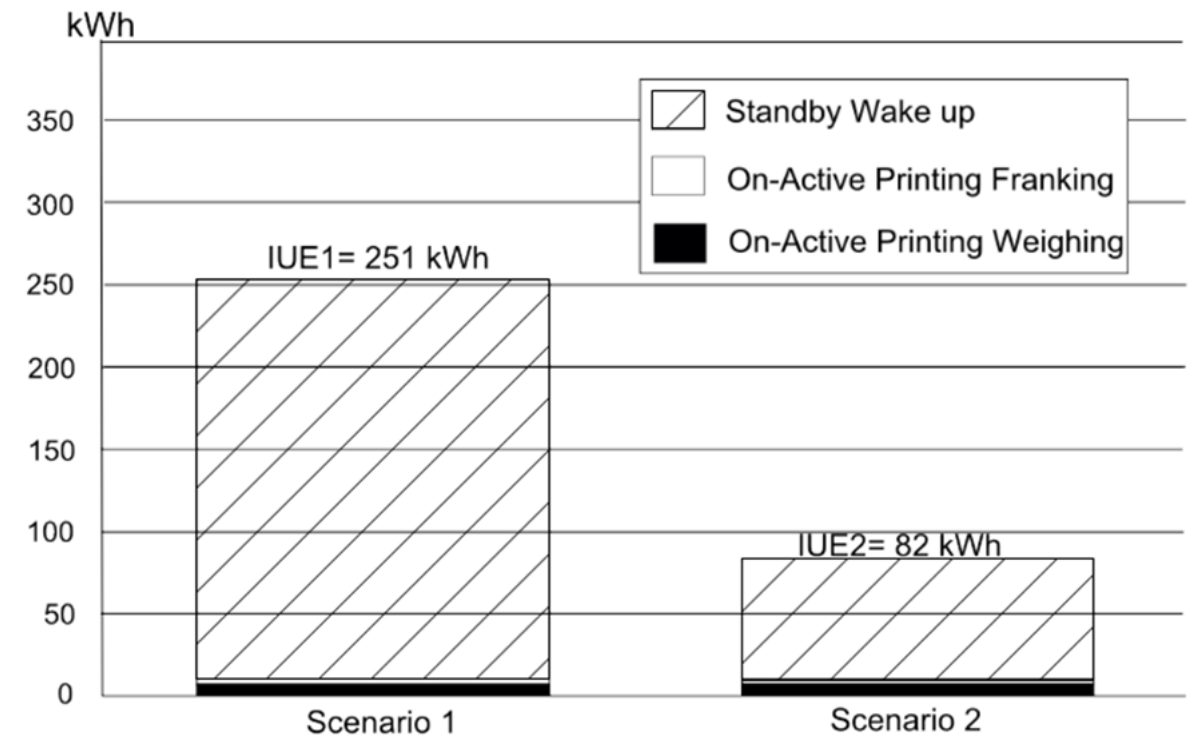

Figure 3:

IUE results at planning with a standby mode.

The IUE results in stand-by (hatched area in Figure 3), showed that the average power in standby was $4 \mathrm{~W}$, i.e. four times above the $1 \mathrm{~W}$ target to comply with Energy Star. This issue would have to be brought up again in the following design phases, if nothing more could be done to ensure the compliance during this phase.

\subsubsection{Lifecycle check}

A lifecycle assessment of the product cannot be done during planning (Millet et al. 2007) but the team can use data from the reference product to model its lifecycle (ISO 2002) and then import the results in the lifecycle check tool to compare the product under design with the reference product. The major environmental impacts and the most impacting lifecycle phases can also be identified and kept in mind in the next steps of the project.

After modelling the reference product with an LCA software (EIME® (Bureau Veritas 2012) using EIME 10.0 database in the case of this postage meter), and importing the results into the tool, the environmental assessment was done. In order to 
remain as simple as possible and to avoid redundancy with regulations on substances like REACh or RoHS (Domingo et al. 2011), this simplified tool focuses on a limited number of relevant impact categories, i.e. on Raw Material Depletion (RMD) and Energy Depletion (ED). The design team noticed that the highest impact was on ED during use, followed by manufacturing for both impacts (Figure 4). Besides, the recycling of product fostered "positive" impacts as the precious metals contained in the products are likely to be recycled.

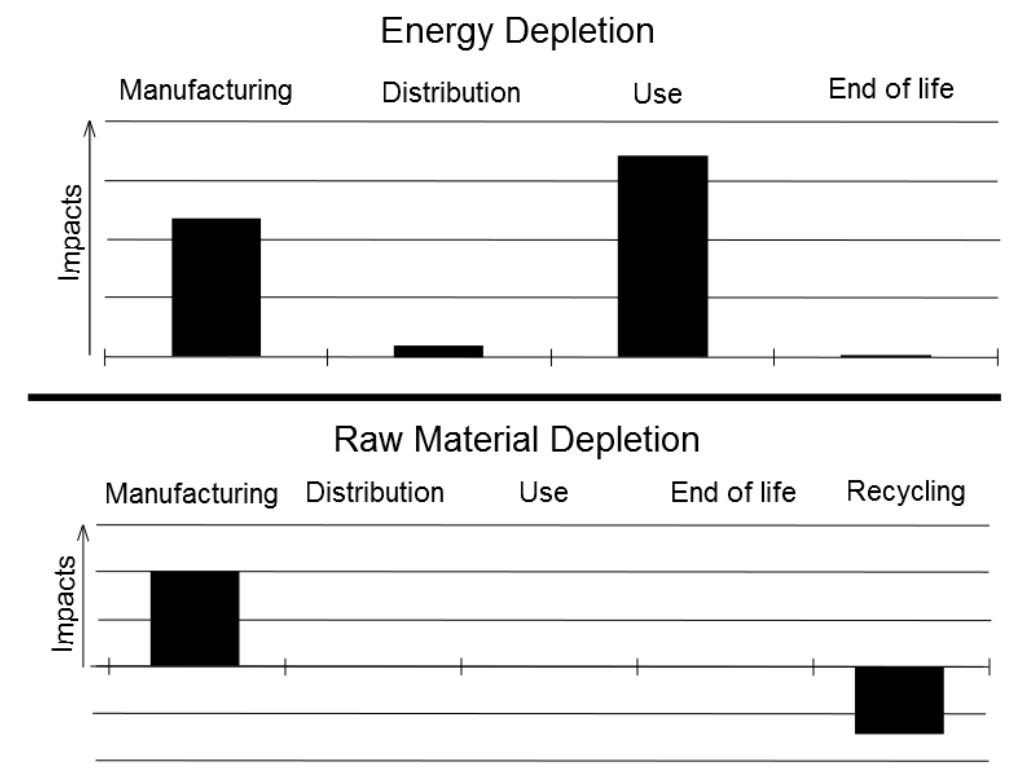

Figure 4: Results of the lifecycle check tool at planning for raw material depletion (RMD) and energy depletion (ED).

\subsubsection{Conclusions at planning}

Despite the little information available at this stage, it was shown that Synergico can be used as early as planning to:

- Set the objectives for the new design;

- Get a first insight of the hotspots of the product;

- Identify a reduced number of guidelines to steer the design strategies;

- Define the environmental performance of the reference product; 
- Be ready to compare design alternatives.

The lack of information about the new product was compensated by the knowledge about the reference product and the knowledge and know-how of the members of the design team.

\subsection{Using Synergico during the other design phases}

During the following design phases, the designers improved their knowledge about the new product and these new data were included into the model. Objectives could be reviewed to correct possible oversights, e.g. compliance with the ErP directive in anticipation of its application in 2015. The guidelines were adapted to the present context by the designers applying the adequate filters.

Typically, the method worked in the same way as in the previous phase and only the major differences will be described in this section.

\subsubsection{Product decomposition}

The functions and product structure were more precisely defined as the design project progressed (Figure 5). 


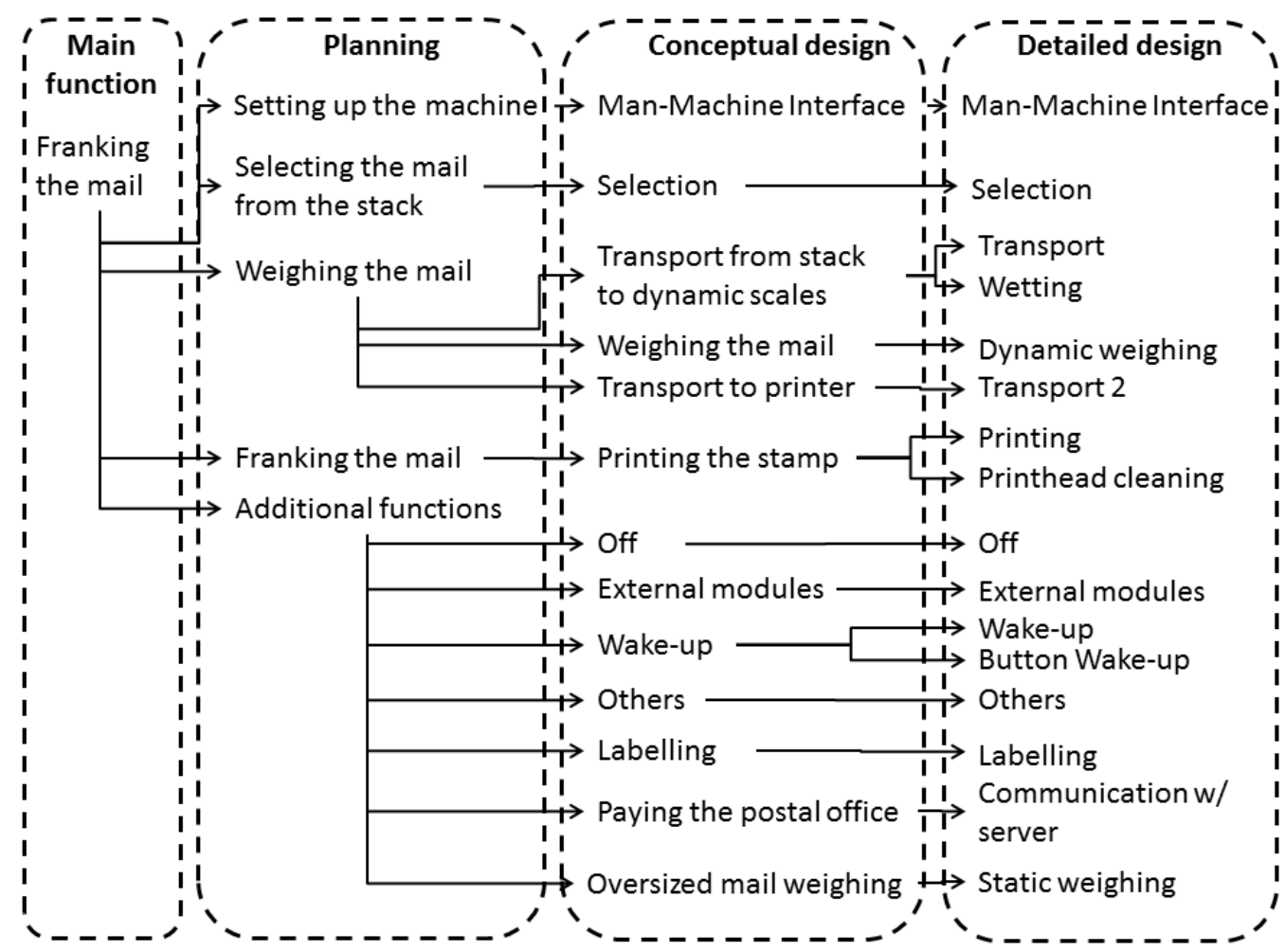

Figure 5: Functional decomposition during planning, conceptual and detailed design.

For instance, the IUE results found during planning showed that the base was the main hotspot of the product. Therefore, rather than modelling the whole product during the conceptual design phase, the designers began focusing on the base and split it into seven elements (Figure 6). Modifying this one sub-assembly allowed the estimation of IUE values that were influenced by the alternative architectures, and this, independently of the rest of the product. It also helped to find the best choice before looking at the whole product. Then, the designers could move on to the next sub-assemblies.

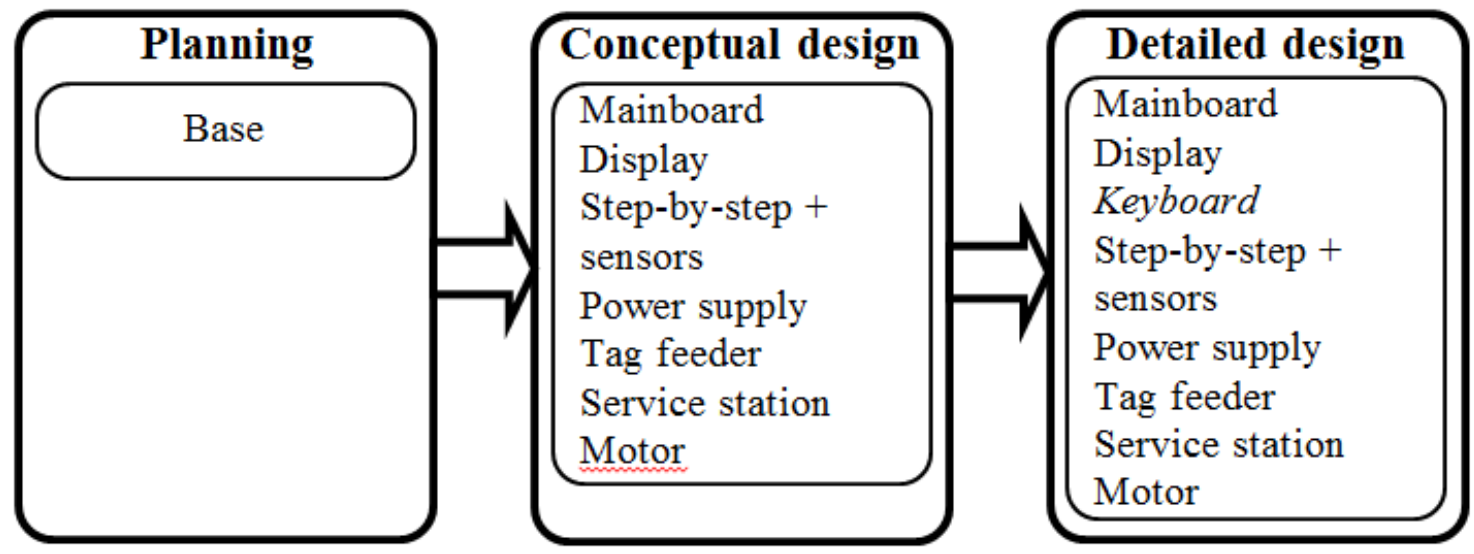

Figure 6: Evolution of the base sub-assembly during the design process. 


\subsubsection{Power}

Before they had a prototype to measure the consumption directly on the product, the experts filled in the estimated power for the different sub-assemblies. They could watch how the indicator evolved with different alternatives and obtained more and more precise values of the indicator.

The team verified whether the targeted objectives were reached or not.

\subsubsection{Lifecycle check tool}

In order to ensure that the new product with good energy efficiency did not have higher environmental impacts on other lifecycle phases or other impact categories, an environmental screening of the product lifecycle needed to be done as early as possible in the design process. The product could then be compared with another product with similar functions. This could also be useful to compare different alternatives during design. Life Cycle Assessment (LCA) as defined in ISO 14040 (ISO 2006) is helpful to identify environmental impacts during the lifecycle of a product and track possible impact trade-offs. However, it presents a number of disadvantages such as its complex application for practitioners, or its need for fully defined products (Millet et al. 2007, Reap et al. 2008, Ramani et al. 2010), It is therefore impossible to use it in early design stages (Telenko et al. 2008) unless dramatic simplifications are made (Nielsen and Wenzel 2002).

Therefore, a simplified lifecycle check tool is included with the Synergico method (Domingo et al. 2011). This tool compares technical alternatives to a reference product which had been previously modelled with a full LCA tool. A database enables designers to pick the components they want to test. A lifecycle impact assessment limited to two 
impact categories, namely Raw Material Depletion and Energy Depletion, is obtained.

The use of this tool depends on the amount of data available during the current design phase (Table 5).

\begin{tabular}{|l|l|}
\hline Design phase & Description \\
\hline Conceptual design & $\begin{array}{l}\text { Comparison of concepts from an environmental viewpoint to select the } \\
\text { most efficient one. E.g. the designers may wonder which solution is the } \\
\text { less impacting between a laser or inkjet printer or a CRT or LCD display } \\
\text { using general data and choose the technology they consider to be the } \\
\text { best option. }\end{array}$ \\
\hline Detailed design & $\begin{array}{l}\text { The components of the product are now known; therefore different } \\
\text { versions of the new postage meter can be modeled in the Lifecycle } \\
\text { check tool. This step is important as new components can be added to } \\
\text { the database. Besides, a comparison with the reference product and } \\
\text { between alternatives of components. }\end{array}$ \\
\hline Trials & $\begin{array}{l}\text { The modeling of the prototype in the lifecycle check tool becomes the } \\
\text { new reference product. }\end{array}$ \\
\hline Production and & $\begin{array}{l}\text { The design is complete and only very little changes might occur like } \\
\text { upgrades of components, or software versions. Nevertheless, these } \\
\text { updates need to be considered in the IUE tool (changes in the } \\
\text { consumptions and time spent in the different modes or to carry out } \\
\text { some functions). These modifications may also affect the results in the } \\
\text { Life Cycle Check tool. }\end{array}$ \\
\hline
\end{tabular}

Table 5: Use of the lifecycle check tool during design.

\subsubsection{Conclusions}

As the project moves forward, more data became available and the designers had a more precise idea of the sub-assemblies, functions, and modes which contribute to energy consumption. They could select the best concepts to fulfil the product specifications and especially the energy consumption targets. Practically, the calculations done at the previous stage were reviewed according to the new ongoing design and gave more accurate results that help make new design decisions.

The energy performances could be used by the marketing department to communicate with customers. 
Eventually, the standby power was $1.01 \mathrm{~W}$ so the compliance with Energy Star had been met (1.0W "to the nearest 0.1 kilowatt-hour").

\section{Discussion}

\subsection{Strengths of Synergico}

The method, as described in the case study, was used in a redesign project concurrently to the design process. The advantage was to use data from a previous project in a reference product. However, in the case of projects where a new product is designed, the use of Synergico is slightly different.

\section{Use of Synergico during a redesign project}

The method and tools are used during the design process. They are helpful:

1. For monitoring quantitatively the energy consumption as early as in the planning stage thanks to the IUE indicator;

2. For identifying the most impacting modes, functions, and sub-assemblies, and therefore to focus on them;

3. For making decisions: the guidelines provide strategies to improve energy efficiency according to the context and to decide if the proposed design at the current phase is satisfying enough to move on to the next phase (they have been incorporated into the practices of the company which participated to this study);

4. Another way of using Synergico is to calculate the IUE indicator in the end of each design phase to validate that a new design is an improvement compared to the reference product, to improve certain sub-assemblies, or to compare alternatives. 
Use of Synergico during a new product design

Even during a new product design, the guidelines are able to provide a set of recommendations and strategies to steer the design towards energy efficiency. Nevertheless, in this case, no older product exists so the reference product needs to be replaced by a similar product from a competitor for example.

\subsection{Limitations of the method}

Several limitations have been identified and will need further research.

\section{Data accessibility}

Data collection has been a critical issue in environmental assessment for many years and the availability of information in the early design stages is an obstacle to the broad diffusion of LCA in companies (Millet et al. 2007). The same conclusion applies to Synergico: in the early design stages, only little information is available and this information is imprecise.

\section{Uncertainty and Nonmonotonicity of data}

Substantial uncertainties exist on the data describing the product consumption and its use. Besides, they evolve as the knowledge about the product progresses, making the IUE indicator results different from one phase to the next because of the over- or underestimation of the input data.

\section{Robustness of the model}

The modelling of users' behaviours appears to be a complex topic and no exhaustive models seem to exist (Sauer et al. 2002). The risk is to choose scenarios which are non- 
representative of the behaviour of most users. This problem is partially bypassed by resorting to the expertise and experience of the corporate designers, with the risk that they are wrong.

\section{Amount of data necessary}

Filling all the power values for each sub-assembly, function and mode may be time consuming. The use of the method might therefore become a burden with complex products. Two approaches seem promising: either using a product previously modelled in Synergico to neglect certain measures, or making some measurements automatic.

\section{Conclusions and perspectives}

This paper proposed a set of one method and three tools aiming at integrating energy efficiency considerations in use into the design process of electrical and electronic equipment. Contrary to most other ecodesign tools, Synergico considers the energy consumption during the different modes of a product while other tools would only consider an average value in use. These three tools are the in-use energy (IUE) consumption tool to estimate detailed product consumption and thus identify the most significant modes, functions, and sub-assemblies; the guideline tool to help the designers find strategies to reduce the consumption of their product; and the lifecycle check tool to avoid pollution transfers. These tools are associated together within an ISO 14062-type ecodesign process in the method.

Synergico still possesses the few limitations described in 5.2. Further research will be necessary to formalize data collection and especially the way functions and subassemblies are identified. Several directions will be explored such as resorting to functional analysis in order to link each function and sub-assembly. A formal procedure 
is indeed needed so as to better consider uncertainties of data and also not to count only on the designers' experience.

Concerning data management, several problems, such as data collection in the beginning of the project, have been identified. One solution to be explored is the creation of a generic, customizable, and evolutive database acting as a backbone for the modelling of the products. Besides, a large amount of data necessary in Synergico may be found in other designers' tools. Thus, providing the possibility to import these data directly in Synergico would be an interesting functionality to quicken the modelling phase. An option is also to include the three tools into systems (e.g. Product Lifecycle Management system) currently in operation in companies to support design activities.

Finally, more practice in companies will be necessary to amend Synergico according to the industrials' needs.

\section{Acknowledgements}

The authors would like to acknowledge the funding from the French EPA ADEME (agreement \#0877C0032), and the participation of Neopost Technologies in the development of this method.

\section{References}

A strategy for competitive, sustainable and secure energy, $\operatorname{COM}(2010) 639$, final. Action plan for energy efficiency: realizing the potential, $\operatorname{COM}(2006) 545$, final. Aoe, T., 2007. Eco-efficiency and ecodesign in electrical and electronic products. Journal of Cleaner Production, 15 (15), 1406-1414.

Bonvoisin, J. et al., 2010. Design for Energy Efficiency: Proposition of a Guidelinesbased Tool. In: D. Marjanović, M. Štorga, N. Pavković, N. Bojčetić, ed. Proceedings of the 11th International Design Conference DESIGN 2010, 17-20 May 2010 Dubrovnik, Croatia. Glasgow: The Design Society, 629-638. 
Brissaud, D., and Tichkiewitch, S., 2001. Product models for life-cycle. Annals of the CIRP, 50 (1), 105-108.

Bureau Veritas, 2012. EIME . Courbevoie, Bureau Veritas. Available from: http://www.codde.fr/page.php?rubrique=6 [Accessed 5 January 2012].

Council Directive 2005/32/EC of 6 July 2005 establishing a framework for the setting of ecodesign requirements for energy-using products and amending Council Directive 92/42/EEC and Directive 96/57/EC and 2000/55/EC of the European Parliament and of the Council.

Council Directive 2009/125/EC of 21 October 2009 establishing a framework for the setting of ecodesign requirements for energy-related products.

Domingo, L., Evrard, D. et al., 2011. Synergico: a new « Design for Energy Efficiency » Method enhancing the Design of more environmentally friendly Electr(on)ic Equipments. In: J. Hesselbach, C. Herrmann, ed. Glocalized solutions for Sustainability in Manufacturing - Proceedings of the 18th CIRP International Conference on Life Cycle Engineering. 2-4 May 2011 Braunschweig, Germany. Heidelberg Dordrecht London New York: Springer, 148-153.

Domingo, L., Mathieux, F., and Brissaud, D., 2012. A new « in-use energy consumption » indicator for the design of energy-efficient electr(on)ics. Journal of Engineering, 23 (3), 217-235.

Elias, E., Dekoninck, E., and Culley, S., 2009. Quantifying the Energy Impacts of Use: A Product Energy Profile Approach. In: $16^{\text {th }}$ CIRP International Conference on Life Cycle Engineering, 4-6 May 2009, Cairo, Egypt.

ENERGY STAR, 2009. Energy Star Program Requirements for Imaging EquipmentEligibility Criteria Version 1.2 [online]. Available from: http://www.energystar.gov/ia/partners/product_specs/program_reqs/Imaging_Eq Equipme_Program_Requirements.pdf [Accessed 14 June 2012].

ENERGY STAR, 2011. Energy Star. Available from: http://www.energystar.gov/ [Accessed 23 September 2011].

Hernandez-Pardo, et al., 2011. Contribution to the characterization of eco-design projects, International Journal of Sustainable Engineering, 4 (4), 301-312.

ISO, 2002. XP ISO/TR 14062 Environmental management - Integrating environmental aspects into product design and development. 
ISO, 2006. ISO 14040:2006 Environmental management - Life Cycle Assessment Principles and framework.

Johansson, G., and Magnusson, T., 2006. Organising for environmental considerations in complex product development projects: implications from introducing a “Green” sub-project. Journal of Cleaner Production, 14 (15), 1368-1376.

Kammerer, D., 2009. The effects of customer benefit and regulation on environmental product innovation. Empirical evidence from appliance manufacturers in Germany. Ecological Economics, 68 (8), 2285-2295.

Kengpol, A., and Booknanit, P., 2011. The decision support framework for developing Ecodesign at conceptual phase based upon ISO/TR 14062. International Journal of Production Economics, 131 (1), 4-14.

Knight, P., and Jenkins, J., 2009. Adopting and applying eco-design techniques: a practitioners perspective. Journal of Cleaner production, 17 (5), 549-558.

Li, H., et al., 2008. Integrating Energy-saving Concept into General Product Design. In: $33^{\text {rd }}$ International Electronics Manufacturing Technology Symposium, 4-6 November 2008 Penang, Malaysia. IEEE, 335-338.

Luttropp, C., and Lagerstedt, J., 2006. EcoDesign and The Ten Golden Rules: generic advice for merging environmental aspects into product development. Journal of Cleaner Production, 14(15-16), 1396-1408.

Millet, D., et al., 2007. Does the potential of the use of LCA match the design team needs? Journal of Cleaner Production, 15(4), 335-346.

Mukherjee, T. et al., 2007. Measurement-based power profiling of data center equipment. In: IEEE Computer Society., 476-477.

Nielsen, P.H., and Wenzel, H., 2002. Integration of environmental aspects in product development: a stepwise procedure based on quantitative life cycle assessment. Journal of Cleaner Production, 10(3), 247-257.

Pahl, G., and Beitz, W., 1996. Engineering design: A systematic approach. $2^{\text {nd }}$ ed., London: Springer.

Pré, 2012a. About SimaPro. Available from: http://www.presustainability.com/content/simapro-lca-software [Accessed 19 March 2012].

Pré, 2012b. ECO-it. Available from: http://www.pre-sustainability.com/content/eco-itecodesign-software [Accessed 19 March 2012].

Ramani, K., et al., 2010. Integrated Sustainable Life Cycle Design: A Review. Journal of Mechanical Engineering, 132(9), 1-15. 
Reap, J., et al., 2008. A survey of unresolved problems in life cycle assessment. The International Journal of Life Cycle Assessment, 13 (5), 374-388.

Rünger, G., et al., 2011. Development of energy-efficient products: Models, methods and IT support. CIRP Journal of Manufacturing Science and Technology, 4 (2), 216-224.

Sauer J., Wiese B.S. and Rüttinger B., 2001. Utilization phase as a critical element in ecological design. In: M.S. Hundal, ed. Mechanical life cycle handbook: good environmental design and manufacturing. New York: Marcel Dekker, 257-284.

Schneider, F., and Salhofer, S., 2008. The development of an ecodesign product - the ecomouse case study. Progress in Industrial ecology - An International Journal, $5(1 / 2)$, p. $102-122$.

Telenko, C., Seepersad, C., and Webber, M., 2008. A compilation of design for environment principles and guidelines. In: Proceedings of IDETC/CIE 2008 ASME 2008 International Design Engineering Technical Conferences \& Computers and Information in Engineering Conference, 3-6 August 2008 New York, USA. 289-301.

Unger, N., Schneider, F., and Salhofer, S., 2008. A review of ecodesign and environmental assessment tools and their appropriateness for electrical and electronic equipment. Progress in Industrial ecology - An International Journal, 5(1/2), 13-29.

Vallet, F., Millet, D., and Eynard, B., 2009. Investigating the use of eco-design guide: presentation of two case studies. In: International Conference on Engineering Design ICED'09, 24-27 August 2009 Stanford, CA, USA.

Vezzoli, C., and Sciama, D., 2006. Life Cycle Design: from general methods of product type specific guidelines and checklists: a method adopted to develop a set guidelines/checklist handbook for the eco-efficient design of NECTA vending machines. Journal of Cleaner Production, 14(17), 1319-1325.

Vienna TU, 2012. Ecodesign PILOT. Available from: http://www.ecodesign.at/pilot/ONLINE/ENGLISH/ [Accessed 19 March 2012].

Wrap, 2012. EDIT - The Eco-Design Indicator Tool. Available from: http://envirowise.wrap.org.uk/uk/Our-Services/Tools/EDIT-The-Eco-DesignIndicator-Tool.html [Accessed 19 March 2012]. 
Zhang, H.C., and Li, H., 2010. An energy factor based systematic approach to energysaving product design. In: CIRP Annals - Manufacturing Technology. Elsevier, 183-186. 